\title{
The Inoculation with an Effecient AMF Strain Decreases the Phosphoric Fertilizer Requirements in Ipomea Batata (L), Lam in Dry Period
}

\author{
Alberto Espinosa Cuéllar, ", Luís Ruiz Martinez ${ }^{1}$, Ramón Rivera Espinosa ${ }^{2}$, \\ Ernesto Espinosa Cuéllar ${ }^{1}$ \\ ${ }^{1}$ Institute of Tropical Crops Research (INIVIT), Santo Domingo, Villa Clara, Cuba \\ ${ }^{2}$ National Institute of Agricultural Sciences (INCA), San José de las Lajas, Mayabeque, Cuba
}

Email address:

fitofer@inivit.cu (A. E. Cuéllar)

${ }^{*}$ Corresponding author

To cite this article:

Alberto Espinosa Cuéllar, Luís Ruiz Martinez, Ramón Rivera Espinosa, Ernesto Espinosa Cuéllar. The Inoculation with an Effecient AMF Strain Decreases the Phosphoric Fertilizer Requirements in Ipomea Batata (L), Lam in Dry Period. Journal of Chemical, Environmental and Biological Engineering. Vol. 3, No. 2, 2019, pp. 13-18. doi: 10.11648/j.jcebe.20190302.11

Received: February 15, 2019; Accepted: March 22, 2019; Published: October 17, 2019

\begin{abstract}
While Ipomeabatata (L), Lam. is a mycotic crop, few results are reported in establishing the requirements of phosphoric fertilizers associated with the inoculation of arbuscular mycorrhizal fungus (AMF) strains. For these purposes, two experiments were carried out, evaluating the response of 'INIVIT B2-2005' or 'CEMSA 78-354'clones to the application of five doses of phosphoric fertilizer with or without the application of Rhizoglomu sirregulare/(INCAM-11) species on a carbonated loose Brown soil, at a random block design with factorial arrangement and four repetitions. The experiments were carried out with 'INIVIT B2-2005' and 'CEMSA 78-354'clones always in the period November - April and they were carried out in two years. The yield of tubers, percentage of mycorrhizal colonization, content of mycorrhizal spores in 50 grams of soil and phosphorus content in the leaf, stem and tuberous root were evaluated. A significant response $(p<0.05)$ to mineral fertilization was found in the yield with an optimum dose of $75 \mathrm{~kg} \mathrm{ha}^{-1}$ which decreased to $50 \mathrm{~kg} \mathrm{ha}^{-1}$ when inoculated with $R$. irregulare, keeping equivalent yields. This effect was similar in both clones and in both years. The inoculation increased the colonization percentage and the spores significantly, and the highest values were always obtained in the treatment of $50 \mathrm{~kg} \mathrm{ha}^{-1}$ of $\mathrm{P}_{2} \mathrm{O}_{5}$, lower and higher fertilizations had lower values. The phosphorus contents in different organs also presented a similar response. It is concluded that the inoculation of an efficient AMF strain causes an adequate mycorrhizal functioning in presence of medium doses of fertilizers, guaranteeing high yields with lower doses of these ones.
\end{abstract}

Keywords: Colonization, Doses, Fertilizations, Spores, Yield

\section{Introduction}

The need of phosphorus in the plant was discovered by Justus von Liebig in 1840 who demonstrated the importance of this element in plant nutrition [26]. The requirements of $\mathrm{P}$ in the sweet potato plant are lower than those of $\mathrm{K}$ and $\mathrm{N}$; however, the beneficial effects of $\mathrm{P}$ are clearly shown in the increase of the tubers average weight, as well as in the proportion of commercial tubers [20].

In comparison with the other essential nutrients, phosphorus $(\mathrm{P})$ is the least mobile nutrient in the soil and the efficiency in the absorption of phosphoric fertilizers by plants can be as low as $20 \%$, and it is often the main limiting factor for plant growth [23]. The mycorrhizal symbiosis is a mutually beneficial mechanism for plants and this type of fungus, through it the fungal structures guarantee nutrients and water and the plants carbon products. It is recognized that mycorrhizal plants can increase the soil phosphorus absorption, being one of the best documented effects of this symbiosis [24].

In recent years from the development of inoculants that are applied in low quantities, from inoculation methods adapted to this crop and from a group of regularities in behavior of the efficient AMF strains, it has been possible to develop a 
system of efficient strains management according to the edaphic environment in which the crops are grown, which guarantees an effective mycorrhizal functioning and the mycorrhization benefits $[2,20,18,19]$.

One of the most well-known effects of an effective mycorrhizal functioning is the increase in the efficiency of absorption of nutrients and therefore the decrease of the fertilizers doses for high yields; however, the symbiosis for an optimum functioning requires a supply of nutrients that is taken more efficiently by these plants. Lower doses limit functioning and high ones inhibit it [18].

Sweet potato (Ipomea batata (L), Lam.) is a highly dependent crop on mycorrhization. Previous results at the level of field experiments in sweet potato, however it was reported that Rhizoglomus irregulare behaved as an efficient strain for this crop in Carbonated Loose Brown soils and its inoculation originated an effective mycorrhizal functioning and decreases in the requirements of mineral fertilizers, it did not work with experimental schemes of response curves to each of the macronutrients and therefore, it could not find the specific effect on one or another primary macronutrient [20].

Therefore, the present work was carried out with the objective of establishing the beneficial effects of the inoculation of an efficient strain of AMF on the requirements of phosphoric fertilizer of sweet potato in the dry season. In other works the specific effects on the requirements of nitrogen and potassium fertilizers are discussed.

\section{Materials and Methods}

The research was carried out at the Research Institute of Tropical Roots and Tuber Crops (INIVIT) on a carbonated loose brown soil [5]. Cataloged as Phaeozems haplic calcaric in correspondence with the World Reference Base [27]. In the slightly rainy period (November - April), characterized by an accumulated rainfall of $30.53 \mathrm{~mm}$ and average temperatures of 22.33, very similar in the two years of work and representative of the region.

The soils where the works were done presented a reaction between neutral and slightly alkaline, associated in the latter case with the presence of free carbonates and they correspond with typical values for this type of soil. With respect to organic matter, the values obtained were low which indicates the various processes of soil degradation. The available phosphorus $\left(\mathrm{P}_{2} \mathrm{O}_{5}\right)$ contents were low. In relation to interchangeable cations, calcium presented high values and $\mathrm{Mg}$ average values, and in both typical cases of these soils. The exchangeable $\mathrm{K}$ presented medium to high values, although in relation to the contents of $\mathrm{Ca}^{+} \mathrm{Mg}$ the values were low.

Regarding with the initial number of AMF spores (Table 1), if they were low, they correspond to the values obtained previously in this type of soil and in this same locality and possibly associated with the high fertilizations commonly performed [21].

Table 1. Initial characterization of the soil, in $0-20 \mathrm{~cm}$ depth, in the experimental area.

\begin{tabular}{|c|c|c|c|c|c|c|c|c|c|c|}
\hline & $\mathbf{p H}$ & & $\mathbf{N}$ & M O & $\mathbf{P}_{2} \mathrm{O}_{5}$ & $\mathrm{Ca}$ & Mg & $\mathbf{N a}$ & $\mathbf{K}$ & Esporas en $50 \mathrm{~g}$ \\
\hline & $\mathrm{H}_{2} \mathrm{O}$ & KCL & $\mathrm{g} \mathrm{kg}^{-1}$ & & mg kg- ${ }^{1}$ & $\left(\mathrm{cmol}_{\mathrm{c}} \mathrm{kg}^{-1}\right)$ & & & & \\
\hline Year 1 & 7,3 & 6,2 & 2,10 & 23,7 & 25,0 & 31,14 & 4,89 & 0,38 & 0,82 & 41,00 \\
\hline $\mathrm{Z}_{1-\alpha} * S_{\bar{x}}$ & $\pm 0,07$ & $\pm 0,04$ & $\pm 0,06$ & $\pm 0,16$ & $\pm 0,61$ & $\pm 0,01$ & $\pm 0,01$ & $\pm 0,01$ & $\pm 0,006$ & $\pm 3,91$ \\
\hline Year 2 & 7,1 & 6,0 & 1,55 & 18,8 & 17,7 & 27,21 & 4,11 & 0,39 & 0,58 & 53,00 \\
\hline $\mathrm{Z}_{1-\alpha} * S_{\bar{x}}$ & $\pm 0,09$ & $\pm 0,06$ & $\pm 0,06$ & $\pm 0,12$ & $\pm 0,11$ & $\pm 0,01$ & $\pm 0,01$ & $\pm 0,006$ & $\pm 0,02$ & $\pm 4,07$ \\
\hline
\end{tabular}

$\mathrm{Z} 1-\alpha * \mathrm{~S} \overline{\mathrm{x}}= \pm$ Confidence Interval $(1-\alpha=0.05)$, being $\mathrm{Z} 1=1.96 . *$ Each value is average of 10 composite samples. $\mathrm{pH}$ in $\mathrm{H} 2 \mathrm{O}$ and $\mathrm{KCL}(\mathrm{KCl} 1 \mathrm{M}$ solution $)$ in relation to soil: solution (1:2.5) through the potentiometric6 method. Determination of organic matter through Walkley-Black7's method (oxidation of $\mathrm{C}$ with $0.5 \mathrm{M} \mathrm{K}_{2} \mathrm{Cr}_{2} \mathrm{O}_{7}$ in $\mathrm{H}_{2} \mathrm{SO}_{4}\left(18 \mathrm{M}\right.$ at $98 \%$ ) and validation with $\mathrm{SO}_{4} \mathrm{FeNH}_{4}(0.25 \mathrm{M}$ ) Extraction of P through Machiguin8's method (extractive solution of (NH4) ${ }_{2} \mathrm{CO}_{3}$ with a concentration of $\left.10 \mathrm{gL}-1, \mathrm{pH} 9.0\right)$ and evaluation with $0.05 \mathrm{M} \mathrm{HCl}$ and orange methyl indicator. Extraction of interchangeable cations with $1 \mathrm{M}$ NH4Ac and $\mathrm{pH} 7$ in relation to soil: solution of 1: 5 and shaking for 5 minutes9. The quantification of initial spores of AMF in the soil was carried out according to the modification of Gerdemann and Nicholson's initial protocol (1963).

The experimental area is characterized by a regime of annual rainfall of $1349 \mathrm{~mm}$, distributed in two seasons, the rainy season from May to October, where $78 \%$ of the rainfall occurs and the little rainy season from November to April. The average annual temperatures are of the order of $24.3^{\circ} \mathrm{C}$, the lowest in the dry season with monthly averages between 20.4 and 23.2 that rise up to $25.5-27.0^{\circ} \mathrm{C}$ in the rainy period [9]. In the years of work, the temperatures $\left(24.2^{\circ} \mathrm{C}\right)$ were very similar to the historical record and the precipitations were lightly lower in the first year, although the existence of irrigation diminished the importance of this variation.

In two commercial sweet potato clones, five levels of phosphoric fertilizer were studied in presence or not of the inoculation with Rhizoglomus irregulare/(INCAM-11), in a factorial design of $2 \times 5$, where the factors are the two clones and the combinations of phosphoric fertilizer and inoculation with four repetitions. The experiments were carried out in unison and they were located contiguous and always in the period November - April, during the years 2011-2012. The plots were constituted by an area of $40.6 \mathrm{~m}^{2}$.

The doses of phosphoric fertilizer studied were: $0 ; 25 ; 50$; 75 and $100 \mathrm{~kg} \mathrm{ha}^{-1}$ of $\mathrm{P}_{2} \mathrm{O}_{5}$. In all cases a fixed fund of $90 \mathrm{~kg}$ $\mathrm{ha}^{-1}$ of Nitrogen and $150 \mathrm{~kg} \mathrm{ha}^{-1}$ of $\mathrm{K}_{2} \mathrm{O}$ were used.

Sweet potato clones used were 'INIVIT B2-2005' and 'CEMSA 78-354'. The preparation of the soil and the different tasks of the crop were carried out according to the technical instructions for the cultivation of sweet potato [13]. They are widely used in the Cuban agriculture and they have high productive potentials. The plantation frame of $0.90 \mathrm{x}$ $0.25 \mathrm{~m}$ was used and $25-30 \mathrm{~cm}$ long cuttings were used as a 
planting material. The fertilizer was applied 25-30 days after planting using as carriers the simple superphosphate (0-20-0), the urea (46-0-0) and the potassium chloride (0-0-60). .

The Rhizoglomus irregulare/(INCAM-11)species was used and the inoculant with a concentration of 25 spores $\mathrm{g}^{-1}$, it was produced according to at the Department of Biofertilizers and Plant Nutrition of the National Institute of Agricultural Sciences (INCA), Mayabeque, Cuba [2]. The inoculation was made from a mixture of $0.125 \mathrm{~kg}$ of inoculant per $600 \mathrm{ml}$ $\mathrm{H}_{2} \mathrm{O}\left(35 \mathrm{~kg} \mathrm{ha}^{-1}\right)$ and covering the lower third of the seed [20].

Different variables were evaluated such as: initial analysis of fertility, including content of mycorrhizal spores; percentage of mycorrhizal colonization at 90 days; $P$ contents in the aerial tissue at harvest and the commercial yield of tuberous roots. The sampling and determination methodologies used were the following:

The initial soil sampling was done at $20 \mathrm{~cm}$ depth taking 10 samples in each of the two years. The chemical fertility determinations carried out are described in table 1. For the extraction of spores, it was proceeded according to [6]. Later the spores were washed with distilled water and they were poured in Petri's dish [3].

The spores were counted with the use of the stereoscopic microscope $70 \times$ (Stemi 2000-C) and they were expressed in spores. $50 \mathrm{~g}^{-1}$ of soil.

The percentage of mycorrhizal colonization of the roots was done by plot. For this, the roots of four plants were mottled and washed with running water, removing all types of soil, then air dried them, after the fine rootlets were crumbled, samples of $200 \mathrm{mg}$ were taken and the methodology described by [15]. Was applied to clarify and dye them. The evaluation was made through the intercepts method.

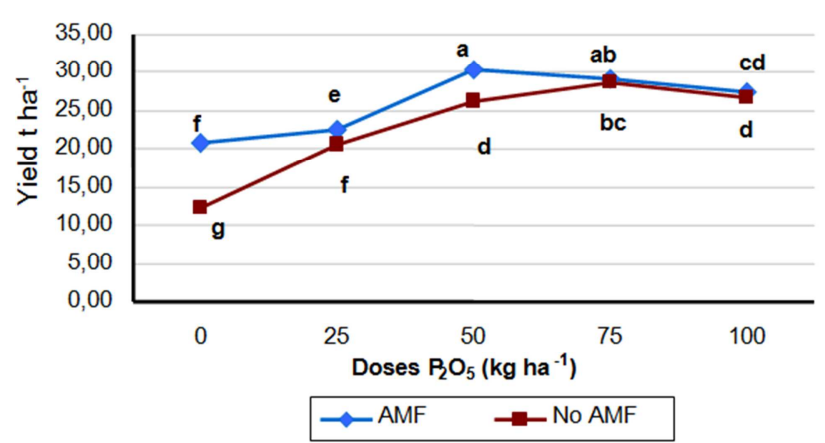

* (a, b, c, d, e) means with uncommon letters differ by Tukey (HSD) for $\mathrm{p}<0.05$

Figure 1. Effect of phosphorus dose and inoculation with R. irregulare/(INCAM-11) on the yield of'INIVIT B2-2005' clone in a dry season.

1. Legend. Doses $=0 ; 25 ; 50 ; 75$ and $100 \mathrm{~kg}$. ha ${ }^{-1}$ of $\mathrm{P}_{2} \mathrm{O}_{5}$. In all cases a fixed fund of $90 \mathrm{~kg}$. ha ${ }^{-1}$ of Nitrogen and $150 \mathrm{~kg}$. ha ${ }^{-1}$ of $\mathrm{K}_{2} \mathrm{O}$; AMF inoculation with $R$. irregulare, No AMFnoinoculation with $R$. irregulare

The foliar content of $\mathrm{P}\left(\mathrm{g} \mathrm{kg}^{-1}\right)$ was made at the harvest time. Four plot/ plants were taken which were subdivided into leaves, stems and tuberous roots, obtaining a representative sample of the different organs of the plant for each plot. Foliar analyzes were performed according to [14].

The yield was determined from the sampling of 24 plot / plants at the harvesting time 5 months after planting and it was expressed in tha- 1 of tuberous roots.

The statistical package of the Program was used. In the case of existing significant differences, the treatments were certified according to Tukey's multiple comparison test $(\mathrm{p} \leq$ $0.05)[25]$.

\section{Results and Discussion}

Figures 1 and 2 illustrate the effect of different doses of $\mathrm{P}_{2} \mathrm{O} 5$ in presence or absence of mycorrhizal inoculation on the yield for 'INIVIT B2-2005' and 'CEMSA 78-354'sweet potato clones in the dry season, for each of the evaluated years. The interaction in each experiment was always significant; therefore the results of the 10 treatments are presented. In both years there was a significant response ( $\mathrm{p} \leq$ 0.05) of both clones to phosphoric fertilization with an increasing response to the application of fertilizer up to $75 \mathrm{~kg}$ $\mathrm{ha}^{-1}$ dose, stabilizing the yield with higher doses.

In presence of the inoculation of the efficient strain of $\mathrm{AMF}$, an increasing response to fertilization is also found and the maximum yields are obtained in presence of $50 \mathrm{~kg} \mathrm{ha}^{-1}$. The maximum yields obtained with and without inoculation of the order of $30 \mathrm{t} \mathrm{ha}^{-1}$ were similar statistically.

The inoculation with the efficient strain brings about a saving of $34 \%\left(25 \mathrm{~kg} \mathrm{ha}^{-1}\right)$ of the mineral fertilizer in both clones and without varying the criterion of best treatment in each year, presenting a high reproducibility.

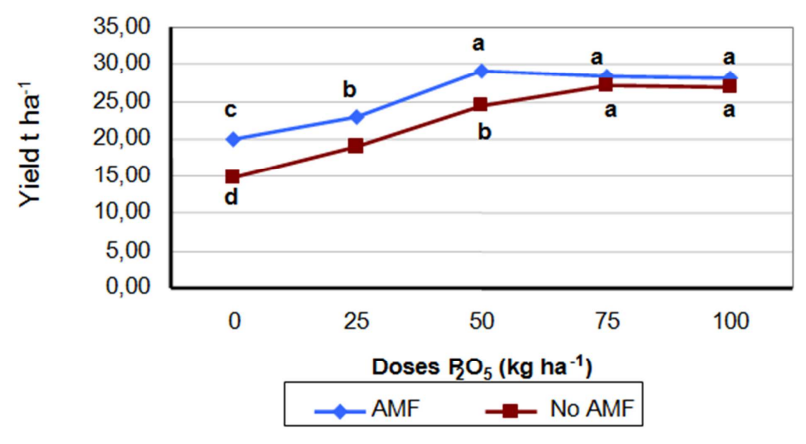



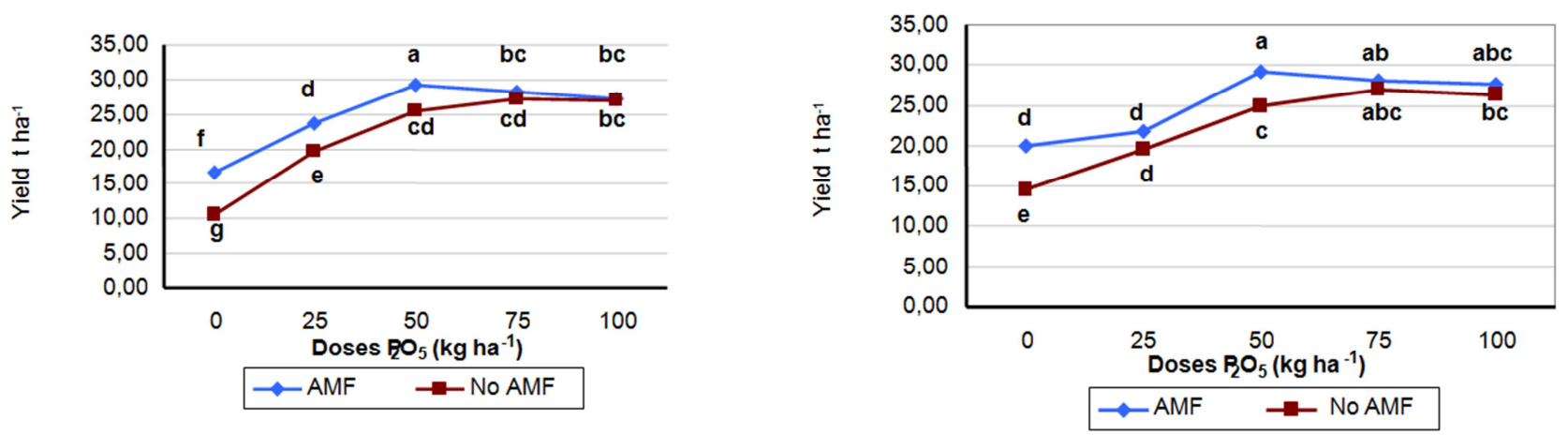

* (a, b, c, d, e) means with uncommon letters differ by Tukey (HSD) for $\mathrm{p}<0.05$

Figure 2. Effect of phosphorus dose and inoculation with R. irregulare (INCAM-11) on the yield of 'CEMSA 78-354' clone in the dry season.

2. Legend. Doses $=0 ; 25 ; 50 ; 75$ and $100 \mathrm{~kg}$. ha ${ }^{-1}$ of $\mathrm{P}_{2} \mathrm{O}_{5}$. In all cases a fixed fund of $90 \mathrm{~kg}$. ha ${ }^{-1}$ of Nitrogen and 150 kg. ha ${ }^{-1}$ of $\mathrm{K}_{2} \mathrm{O}$; AMF inoculation with $R$. irregulare, No AMFnoinoculation with $R$. irregular.

To maximize crop yield per unit area, chemical fertilizers are mainly used. Phosphorus is one of the essential minerals that are added to most plant species, including sweet potato cultivation [1]: These authors' high light significant increases in total yield and commercial roots.

The inoculation with AMF decreases the requirements of mineral fertilizers (NPK) guaranteeing high yields and state that sweet potato plants tend to show their best quality performance and yield when superphosphate is applied and when it is combined with the inoculation of arbuscular mycorrhizal fungus [16].

However, the specific amounts of decreasing in fertilizer requirements due to the presence of an effective mycorrhization will depend on the level of yield achieved and the availability of the nutrient on the soil [17].

Table 2 shows the effect of phosphorus dose on the percentage of colonization and the number of spores in $50 \mathrm{~g}$ soil for 'INIVIT B2-2005' and 'CEMSA 78-354'sweet potato clones during two years. Similar to the yield, it was always found a significant interaction.

It is observed that regardless of the fact that the inoculation always originated high percentages of colonization and spores, the highest values were reached in the treatment where $50 \mathrm{~kg} \cdot \mathrm{ha}^{-1}$ of $\mathrm{P}_{2} \mathrm{O}_{5}$ was inoculated with the $R$.irregularestrain, whose values oscillate between 62 and $64 \%$ for colonization and around 350 spores in $50 \mathrm{~g}$ with significant differences over the other treatments.

The colonization percentages reached are typical of an effective mycorrhization according to the results obtained by various authors both in the sweet potato itself as in other dependent crops of the mycorrhization [20, 4, 11].

Regarding the spores, although the results seem to be more dependent on the crop as such, similar contents were reported by inoculating this strain in the banana in this same type of soil [21].

Mycorrhizal plants require a nutrient supply for plants growth and mycorrhizal functioning. In the studied soils, although fertility is not low, fertilizer doses are required to obtain high yields and an effective mycorrhization if it increases nutrients intake, they require medium doses of fertilizers to guarantee the nutritional requirements, characteristics of the high yields $[10,18]$.

Several researchers in Cuba have obtained similar results in relation to the low availability of nutrients which limits the mycorrhizal functioning and the high availability of these make to decrease the presence of mycorrhizal structures inside the roots, which indicates that the decrease in mycorrhizal effectiveness is a consequence of a bad functioning or inhibition of symbiosis [18, 20, 4].

Table 2. Effect of phosphorus dose and the inoculation of $R$. irregulare on the percentage of mycorrhizal colonization and the number of spores in the rhizosphere of sweet potato clones.

\begin{tabular}{|c|c|c|c|c|c|c|c|c|}
\hline \multirow{2}{*}{ Clon } & \multicolumn{4}{|c|}{ 'INIVIT B2-2005' } & \multicolumn{4}{|c|}{ 'CEMSA 78-354' } \\
\hline & \multicolumn{2}{|c|}{ Colonization (\%) } & \multicolumn{2}{|l|}{ spores in $50 \mathrm{~g}$} & \multicolumn{2}{|c|}{ Colonization (\%) } & \multicolumn{2}{|c|}{ spores in $50 \mathrm{~g}$} \\
\hline $\begin{array}{l}\mathrm{P}_{2} \mathrm{O}_{5} \\
\left(\mathrm{~kg} \mathrm{ha}^{-1}\right)\end{array}$ & AMF & $0 \mathrm{AMF}$ & $\mathrm{AMF}$ & $\begin{array}{l}0 \\
\mathrm{AMF}\end{array}$ & AMF & $0 \mathrm{AMF}$ & $\mathrm{AMF}$ & $\begin{array}{l}0 \\
\text { AMF }\end{array}$ \\
\hline 0 & $52,50 \mathrm{c}$ & $9,00 \mathrm{f}$ & $252,77 \mathrm{e}$ & $60,77 \mathrm{~h}$ & $50,25 \mathrm{c}$ & $8,75 \mathrm{f}$ & $254,15 \mathrm{e}$ & $60,55 \mathrm{~h}$ \\
\hline 25 & $57,50 \mathrm{~b}$ & 9,75 ef & $307,52 \mathrm{c}$ & $72,30 \mathrm{~g}$ & $59,50 \mathrm{~b}$ & 9,25 ef & $313,10 \mathrm{c}$ & $72,42 \mathrm{~g}$ \\
\hline 50 & $63,75 \mathrm{a}$ & 10,00 ef & $355,25 \mathrm{a}$ & $77,30 \mathrm{fg}$ & $63,00 \mathrm{a}$ & $10,25 \mathrm{ef}$ & $347,27 \mathrm{a}$ & $75,77 \mathrm{~g}$ \\
\hline 75 & $53,50 \mathrm{c}$ & $11,75 \mathrm{e}$ & $326,00 \mathrm{~b}$ & $87,72 \mathrm{f}$ & $51,50 \mathrm{c}$ & $11,25 \mathrm{e}$ & $321,45 \mathrm{~b}$ & $82,00 \mathrm{f}$ \\
\hline 100 & $39,50 \mathrm{~d}$ & 10,75 ef & $297,07 \mathrm{~d}$ & $81,00 \mathrm{f}$ & $37,50 \mathrm{~d}$ & 10,50 ef & $289,57 \mathrm{~d}$ & $77,95 \mathrm{fg}$ \\
\hline $\begin{array}{l}\mathrm{ES} \pm \\
\text { year } 2\end{array}$ & $0,54 *$ & & $1,20 *$ & & $0,48^{*}$ & & $1,28^{*}$ & \\
\hline 0 & $51,75 \mathrm{c}$ & $8,75 \mathrm{f}$ & $251,03 \mathrm{e}$ & $60,54 \mathrm{i}$ & $50,50 \mathrm{c}$ & $8,50 \mathrm{f}$ & $250,65 \mathrm{e}$ & $60,11 \mathrm{i}$ \\
\hline 25 & $57,25 \mathrm{~b}$ & $10,00 \mathrm{ef}$ & $306,28 \mathrm{c}$ & $70,27 \mathrm{~h}$ & $58,25 \mathrm{~b}$ & $9,50 \mathrm{ef}$ & $308,10 \mathrm{c}$ & $69,49 \mathrm{~h}$ \\
\hline 50 & $62,75 \mathrm{a}$ & 10,75 ef & $353,75 \mathrm{a}$ & $76,05 \mathrm{~g}$ & $62,50 \mathrm{a}$ & $10,75 \mathrm{ef}$ & $346,00 \mathrm{a}$ & $74,48 \mathrm{~g}$ \\
\hline
\end{tabular}




\begin{tabular}{|c|c|c|c|c|c|c|c|c|}
\hline \multirow{2}{*}{ Clon } & \multicolumn{4}{|c|}{ 'INIVIT B2-2005' } & \multicolumn{4}{|c|}{ 'CEMSA 78-354' } \\
\hline & \multicolumn{2}{|c|}{ Colonization (\%) } & \multicolumn{2}{|c|}{ spores in $50 \mathrm{~g}$} & \multicolumn{2}{|c|}{ Colonization (\%) } & \multicolumn{2}{|c|}{ spores in $50 \mathrm{~g}$} \\
\hline 75 & $52,50 \mathrm{c}$ & $12,00 \mathrm{e}$ & $323,25 \mathrm{~b}$ & $81,60 \mathrm{f}$ & $51,75 \mathrm{c}$ & $11,75 \mathrm{e}$ & $319,45 \mathrm{~b}$ & $81,24 \mathrm{f}$ \\
\hline 100 & $39,50 \mathrm{~d}$ & 10,25 ef & $298,75 \mathrm{~d}$ & $80,40 \mathrm{fg}$ & $38,25 \mathrm{~d}$ & 10,50 ef & $292,33 \mathrm{~d}$ & $79,41 \mathrm{f}$ \\
\hline $\mathrm{ES} \pm$ & $0,67 *$ & & $1,11^{*}$ & & $0,52 *$ & & $0,72 *$ & \\
\hline
\end{tabular}

*The means of each factorial dose $\mathrm{x}$ AMF for each variable in each clone and year are present.

ES corresponds to the interaction error. Different letters in each grouping of two columns and 10 treatments carry to different means by Tukey (HSD) for $\mathrm{p}<0.05$.

Legend. Doses $=0 ; 25 ; 50 ; 75$ and $100 \mathrm{~kg}$. ha ${ }^{-1}$ of $\mathrm{P}_{2} \mathrm{O}_{5}$. In all cases a fixed fund of $90 \mathrm{~kg}$. ha ${ }^{-1}$ of Nitrogen and $150 \mathrm{~kg}$. $\mathrm{ha}^{-1}$ of $\mathrm{K}_{2} \mathrm{O}$; AMF inoculation with $R$. irregulare, 0 AMFnoinoculation with $R$. irregulare, year 1 (2011) year 2 (2012).

Figures 3 and 4 show the contents of phosphorus in the different organs for both clones and years. In any of the cases, the $\mathrm{P}$ contents of the inoculated treatment in presence of $50 \mathrm{~kg} \mathrm{ha}^{-1}$ of $\mathrm{P}_{2} \mathrm{O}_{5}$ presented the highest values; however it was in the tubers the organ in which these values were always higher than those of the non-inoculated homologous treatment and even in 'CEMSA 78-354'clone they were also significantly superior to the optimal treatment of mineral fertilization that received doses of $75 \mathrm{~kg} \mathrm{ha}^{-1}$.

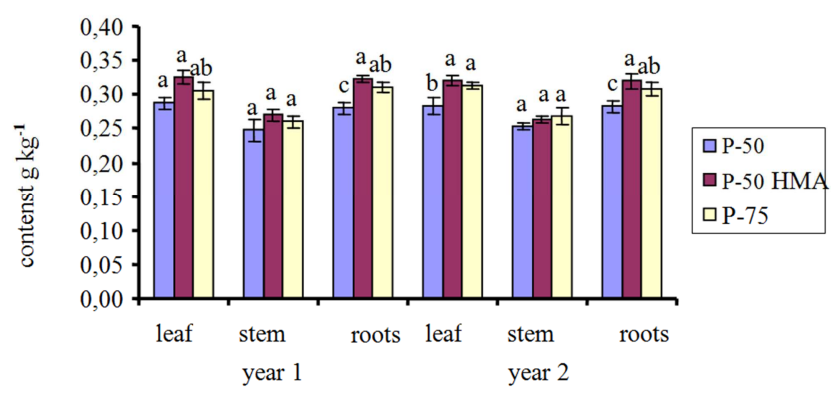

* (a, b, c) means with uncommon letters differ by Tukey (HSD) for $\mathrm{p}<0.05$

Figure 3. Phosphorus content in the dry season in'INIVIT-B2-2005'clone.

3. Legend: P-50 (50 kg ha ${ }^{-1}$ of $\left.\mathrm{P}_{2} \mathrm{O}_{5}\right), \mathrm{P}-50$ AMF (50 kg ha ${ }^{-1}$ of $\mathrm{P}_{2} \mathrm{O}_{5}$ inoculated with R. irregulare/ (INCAM-11) strain, $\mathrm{P}$ $75\left(75 \mathrm{~kg} \mathrm{ha}^{-1}\right.$ of $\left.\mathrm{P}_{2} \mathrm{O}_{5}\right)$.

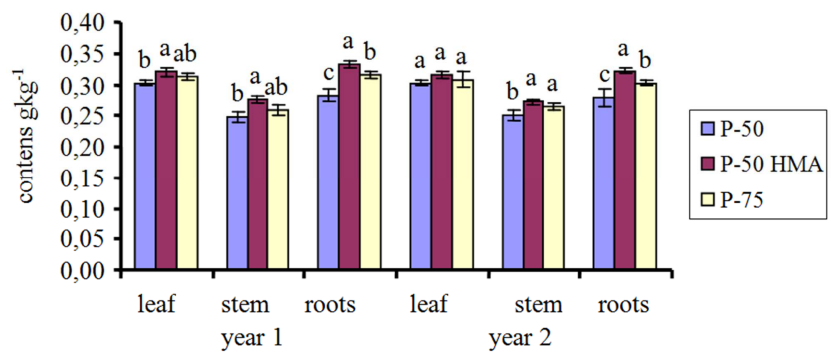

* ( $\mathrm{a}, \mathrm{b}, \mathrm{c})$ means with uncommon letters differ by Tukey (HSD) for $\mathrm{p}<0.05$

Figure 4. Phosphorus content in the dry season in'CEMSA 78-354'clone.

4. Legend: P-50 (50 kg ha ${ }^{-1}$ of $\left.\mathrm{P}_{2} \mathrm{O}_{5}\right), \mathrm{P}-50$ AMF $\left(50 \mathrm{~kg} \mathrm{ha}^{-1}\right.$ of $\mathrm{P}_{2} \mathrm{O}_{5}$ inoculated with $R$. irregulare/(INCAM-11) strain, $\mathrm{P}-75$ ( $75 \mathrm{~kg} \mathrm{ha}^{-1}$ of $\mathrm{P}_{2} \mathrm{O}_{5}$ ).

Generally, in the leaves no differences were found between the treatments, even if they were found in the yield and in the stems the effect was only found in the 'CEMSA 78-354' clone, in which the highest contents were also associated with the highest yields.

The differences found in the behavior of the organs in terms of reflecting the effect of the treatments may be at least partially related to the fact that the sampling was done at harvest and the plant has already favored the translocation of photosylates and nutrients to the tuberose root at this time and everything seems to indicate that at this physiological stage, it is in that organ where the differences in the capacity of the nutrient supply schemes to satisfy the requirements of the crop will be established.

Although the AMF symbiosis facilitates the absorption of nitrogen and phosphorus to the plant, this symbiosis is more important for the absorption of phosphorus. Up to $25 \%$ of the nitrogen in the plant and $80 \%$ of the phosphorus in the plant can be of mycorrhiza origin $[7,12]$.

The effectiveness of the inoculation not only depends on the proper selection of the strains of AMF used, but on the supply of nutrients or richness of the substrate in which the plants grow, being the edaphic environment determinant in the effective management of the inoculation, it not only depended on the selection of efficient strains [18].

The results show the feasibility of integrating mycorrhizal inoculants with nutrient supply schemes, in this case based on fertilizers, guaranteeing high yields and an effective mycorrhizal functioning in presence of medium doses of fertilizers and increasing the efficiency in the absorption of this nutrient.

\section{Conclusions}

The management of the arbuscular mycorrhizal symbiosis through the inoculation of effective strains is integrated into the phosphorus supply schemes of Ipomea batata (L), Lam culture, based on mineral fertilization. The inoculation guarantees an adequate mycorrhizal functioning; high yields and increases the efficiency of phosphoric fertilization, reducing the requirements of phosphoric fertilizers at a $33 \%$ in the inoculated and cultivated plantations in carbonated loose Brown soils. Fertilizer applications lower or higher to these requirements decrease the mycorrhizal functioning and limit the effectiveness and benefits of the inoculation.

\section{References}

[1] El-Sayed, H. E. A, A. S. El-Dean, S. Ezzat, and A. H. A. ElMorsy. Responses of productivity and quality of sweet potato to phosphorus fertilizer rate and application methods of the humicacid. Int. Res. J. Agric. Sci. Soil Sci., 1: 383-393. 2011. 
[2] Fernández, F.; Gómez, R.; Martínez, M. A.; Noval, B. M. de la.; Rivera R. Mycorrhizal inoculant product. Patent No. 22 641. Cuba, 2000.

[3] Gerdemann, J. W.; Nicholson, T. H. Spore of mycorrhizaeendogone species extracted from soil by wet sieving and decanting. Trans. Br. Mycol. Soc. vol. 46, p. 235244. 1963.

[4] González, P. J.; Ramírez, J. F.; Morgan, O.; Rivera, R.; Plana, R. Contribution of arbuscularmycorrhizal inoculation to the reduction of phosphorus fertilization in Brachiariadecumbens. Tropical Crops, vol. 36, no. 1, pp. 135-142 January-March. Digital ISSN: 1819-4087.2015.

[5] Hernández, J. A.; Pérez, J. J. M.; Bosch, I. D. and Castro, S. N. Classification of the soils of Cuba. Editions INCA, Cuba, 93 p. ISBN: 978-959-7023-77-7.2015.

[6] Herrera, R. A .; Ferrer, R. L .; Furrazola, E .; Orozco, M. O. Strategy for the operation of VA mycorrhizae in a tropical forest. Biodiversity in Latin America. Ecosystems, evolution and social processes. Mérida, Mexico: Ibero-American Program of Science and Technology for Development. Subprogram XII, Biological Diversity. 1995.

[7] Hodge A, Fitter A . Substantial nitrogen acquisition by arbuscularmycorrhizal fungi from organic material has implications for $\mathrm{N}$ cycling. Proceedings of the National Academy of Sciences USA107: 13754-13759. 2010.

[8] H. S. Abdel-Razzak, A. G. Moussa, M. A. Abd El-Fattah and G. A. El-Morabet. Response of Sweet Potato to Integrated Effect of Chemical and Natural Phosphorus Fertilizer and Their Levels in Combination with Mycorrhizal Inoculation. Journal of Biological Sciences, 13: 112-122. 2013.

[9] INSMET. Institute of Meteorology. Settling sheets of the daily meteorological variables. Weather station No.326, Santo Domingo, Villa Clara, Cuba. 2013.

[10] Jeffries P, Gianinazzi S, Perotto S, Turnau K, Barea JM. The contribution of arbuscularmycorrhizal fungi in sustainable maintenance of plant health andsoil fertility. Biol. Fértil. Soils 37: $1-16.2003$.

[11] oão, J. P.; Espinosa, A; Ruíz, L; Simó, Jy Rivera R. Effectiveness of strains of AMF in the cultivation of cassava (Manihotesculentacrantz) in two soil types. Tropical Crops, vol. 37, no. 1, pp. 48-56. ISSN 0258-5936. 2016.

[12] Liu A, Plenchette C, Hamel C . Soil nutrient and water providers: how arbuscularmycorrhizal mycelia support plant performance in a resource limited world. In: Hamel C, Plenchette C (eds) Mycorrhizae in crop production. Haworth, Binghampton, pp 37-66.2007.

[13] MINAG. Technical instructions on the cultivation of sweet potatoes. Ministry of Agriculture. SEDARI / AGINFOR. City of Havana, Cuba. 24 pp. 2011.

[14] NRAG 564. Plant analysis. Foliar analysis. Test methods. NRAG 564: 82. City of Havana: MINAG.13p.1982.

[15] Phillips, J. M. y Hayman, D. E. Improved procedures for clearing groots and staining parasitic and vesiculararbuscularmycorrhizal fungi for rapid assessment of infection. Trans. Br. Mycol. Soc., vol. 55, p. 158-161. 1970.
[16] Ruiz, L. Effectiveness of mycorrhizal associations in roots and tubers in two soil types. [Online $\mathrm{PhD}$ thesis]. Havana: Agrarian University of Havana (UNAH). National Institute of Agricultural Sciences (INCA) .101p. [In line]. [Accessed: April 2014]. Available at: $<$ http://www.inca.edu.cu/redmicorrizas/docs/posgrados/resum en /2.pdf. $>$.2001.

[17] Rivera, R. and Fernández, Kalyanne. Scientific-technical bases for the efficient management of agricultural systems mycorrhized. In: Efficient management of mycorrhizal symbiosis, a path towards sustainable agriculture. Case study: the Caribbean. Havana: National Institute of Agricultural Sciences (INCA). p. 51-94. ISBN: 959-7023-24-5. 2003.

[18] Rivera, R.; Fernández, F.; Fernández, Kalyanne, Ruiz, L.; Sánchez, C.; Riera, M. Advances in the management of effective arbuscularmycorrhizal symbiosis in tropical ecosystems. In: Hamel C., Plenchette C. (Eds.) Mycorrhizae in Crop Production. Haworth Press, Binghamton, N. Y., pp. 151196. Hard Cover ISBN: 978-1-56022-306-1; Soft Cover ISBN: 978-1-56022-307-8.2007.

[19] Rivera, R.; González, P. J.; Hernández, A.; Martín, Gloria, Ruiz, L.; Fernández, Kalyanne, Simó, J.; García, Milagro, Pérez, A.; Riera, M.; Bustamante, C.; Joao, J. P. and Ruiz, M. The importance of soil environment and $\mathrm{pH}$ on the effectiveness and recommendation of efficient strains of AMF for the inoculation of crops. [CD-Rom] In: VIII Congress of the Cuban Society of Soil Science. (June 2 to 5, 2015) Memories. Havana Cuba. ISBN 978-959-296-039-8. 2015.

[20] Ruiz, L; J. Simo and R. Rivera. Mycorrhizae in tropical crops. A contribution to agri-food sustainability. - Madrid: Editorial Académica Española, ISBN: 978-3-8484-5382-5, 2012. - 239 p. 2012.

[21] Simó González J .; L. Ruiz Martinez, R. Rivera Espinosa. Management of the arbuscularmycorrhizal symbiosis and nutrient supply in plantations of banana cultivar 'FHIA-18' on soft carbonated Brown soils. Tropical Crops, vol. 36 no. 4, pp. 43-54. ISSN 0258-5936.2015.

[22] Smith SE, Smith FA, Jakobsen I . Mycorrhizal fungi can dominate phosphate supply to plants irrespective of growth response. Plant Physiology 133: 16-20. 2003.

[23] Smith SE, Read DJ. Mycorrhizal symbiosis (Harcourt Brace, San Diego). 2008.

[24] Smith, S. E., and F. A. Smith.. Roles of arbuscularmycorrhizas in plant nutrition and growth: New paradigms from cellular to ecosystem scales. Ann. Rev. Plant Biol. 62: 227-50. doi: 10.1146/annurev-arplant-042110-103846.2011.

[25] SPSS. Statistical Package for the Social Sciences. Version 2.1. Manual of the user of the basic IBM system. [Online] [Consulted: April 2014]. Available at: http://www01.ibm.com/sofware/en/stats21/.2012.

[26] Villegas, R., V Gómez, A. Matos and M. López. The phosphorus in the agriculture of Cuba. Presentations of the first National Meeting of Agrochemistry. Havana. ACC.69 p. 1983.

[27] WRB (World reference base for soil resources). International soil classification system fornaming soils and creating legends for soil maps. World Soil Reports no. 106. FAO, Roma, 81 p. ISBN: 978-92-5-108369-7. ISSN: 0532-0488. 2014. 